Published in final edited form as:

Curr Opin Virol. 2015 April ; 11: 1-6. doi:10.1016/j.coviro.2014.12.001.

\title{
New Insights into Innate Immune Restriction of West Nile Virus Infection
}

\author{
Helen M. Lazear ${ }^{\mathrm{a}}$ and Michael S. Diamonda,b,c,d, ${ }^{*}$ \\ aDepartment of Medicine, Washington University School of Medicine, St Louis, MO 63110, USA \\ bDepartment of Molecular Microbiology, Washington University School of Medicine, St Louis, MO \\ 63110, USA \\ 'Department of Pathology and Immunology, Washington University School of Medicine, St Louis, \\ MO 63110, USA \\ ${ }^{d}$ Center for Human Immunology and Immunotherapy Programs, Washington University School of \\ Medicine, St Louis, MO 63110, USA
}

\begin{abstract}
West Nile virus (WNV) is an encephalitic flavivirus that has provided a valuable experimental system for studying viral pathogenesis and immunity. Although in vitro approaches and mouse models of infection have identified pattern recognition receptor and interferon pathways that control WNV infection, our appreciation of specific antiviral effectors has been more limited. In this review, we highlight recent advances in our understanding of the host factors that restrict WNV infection in mammals and insects, especially those resulting from large-scale screening approaches.
\end{abstract}

\section{Introduction}

West Nile virus (WNV) is an encephalitic flavivirus that is maintained in an enzootic cycle between Culex mosquitoes and birds [1,2], and is transmitted to humans and other vertebrates as incidental, dead-end hosts [3]. This biology has interesting implications for virus-host interactions and human disease: since humans do not transmit WNV to mosquitoes, selective pressure from the human immune response does not drive WNV evolution or impact virus transmission in nature. WNV infection provides an excellent model for understanding virus-host-vector interactions, due to its high level of infectivity in mammalian and insect cells in culture, the availability of mouse models that mimic features of human disease, and its importance as a zoonotic agent of human and animal disease.

\footnotetext{
(C) 2014 Elsevier B.V. All rights reserved.

"Corresponding Author: 660 S. Euclid Ave., Box 8051, St. Louis, MO 63110, USA, Phone: 314-362-2842, MSD: diamond@borcim.wustl.edu; HML: hlazear@dom.wustl.edu.

Publisher's Disclaimer: This is a PDF file of an unedited manuscript that has been accepted for publication. As a service to our customers we are providing this early version of the manuscript. The manuscript will undergo copyediting, typesetting, and review of the resulting proof before it is published in its final citable form. Please note that during the production process errors may be discovered which could affect the content, and all legal disclaimers that apply to the journal pertain.
} 
After its initial introduction into New York City in 1999, WNV rapidly spread across the continental United States and by 2004 had become endemic in most parts of the country [4]. Its importance as an ongoing public health concern is demonstrated by recent outbreaks of WNV encephalitis, including a large outbreak in Texas in 2012 [5], the spread of a lineage 2 strain across Europe since 2008 [6,7], and the emergence in Australia in 2011 of encephalitis caused by the Kunjin strain of WNV [8]. The latter two are examples of human disease caused by WNV strains that had rarely been associated with neuroinvasive disease in the past. Although the basis for the emergence of human disease from previously attenuated or avirulent WNV strains remains unclear, these outbreaks highlight the continued importance of understanding the biology of WNV pathogenesis and its interaction with its hosts.

\section{WNV infection paradoxically is restricted by the DNA sensor cGAS}

Several studies have shown that WNV infection is detected by pattern recognition receptors (PRRs) in the Toll-like receptor (TLR) and RIG-I-like receptor (RLR) families of RNA sensors [9-17] (Figure 1). However, recent studies have revealed that cGAS [18] and its downstream signaling molecule, STING [19] also restrict WNV infection. These observations were unexpected because cGAS is a DNA-sensing PRR, and had not been reported to control RNA virus infection [20]. Nonetheless, ectopic expression of cGAS inhibited WNV replication and $\mathrm{cGAS}^{-/-}$mice exhibited increased lethality after WNV infection [18]. cGAS signals through the adaptor molecule STING to induce type I interferon (IFN- $\alpha / \beta$ ) production [20]. Consistent with a possible role for cGAS in controlling WNV infection, STING ${ }^{-/}$mice also exhibited increased lethality after WNV infection [19], although this could be explained by cross-talk between STING and RLR signaling pathways [21]. The mechanism by which cGAS becomes activated following WNV infection remains unknown, but possibilities include: viral RNA-binding activity of cGAS, production of cDNA copies of viral sequences by cellular reverse transcriptases [22], or generation of host cell-derived DNA damage-associated molecular patterns (DAMPs) in response to cytopathic effects of virus infection [23].

\section{Genetic screens identify IFN-induced antiviral effector molecules against WNV}

Similar to many other RNA and DNA viruses, IFN- $\alpha / \beta$ is critical for controlling WNV infection and limiting pathogenesis (Figure 1). Early studies used Ifnar ${ }^{-/}$mice to demonstrate an essential role for IFN- $\alpha / \beta$ in controlling WNV $[24,25]$, but the specific mechanisms through which this antiviral effect was exerted remained unknown. IFN- $\alpha / \beta$ signaling induces the expression of hundreds of IFN-stimulated genes (ISGs), and while these presumably encode the effector molecules of an antiviral response, until recently inhibitory mechanisms had been described for only a few ISGs (e.g. Mx1, PKR, RNase L, and OAS) $[26,27]$. One of the key recent advances in our understanding of host factors that restrict WNV (as well as many other viruses) has been the application of large-scale ectopic expression $[28,29]$ or gene silencing $[30,31]$ screens to identify sets of genes that control viral replication in vitro. Such approaches have detected previously described components of the antiviral response (e.g. MDA5, RIG-I, TLR-3, MAVS, IRF-3, JAK2, STAT-2, IRF-9, and PKR) but also have revealed many novel antiviral ISGs, thereby identifying promising 
targets for subsequent mechanistic studies and possible drug development. ISGs that displayed significant antiviral activity against WNV in vitro include: C6orf150, DDX24, HPSE, IFI44L, IFI6, IFITM2, IFITM3, IFRD1, IL13RA1, ISG20, MAFK, NAMPT, PAK3, PHF15, SAMD9L, SC4MOL, and viperin. The antiviral mechanisms of some welldescribed ISGs have been reviewed [27,32], but the mechanisms by which these novel ISGs restrict WNV replication and their roles in controlling WNV pathogenesis remain to be determined. ISGs for which antiviral activity against WNV has been demonstrated in vivo include PKR, RNase L, viperin, and IFIT2 [33-36], several of which control WNV infection specifically in neurons of the central nervous system (CNS). Systems biology approaches will be critical for developing testable hypotheses from these complex datasets [37]. Indeed, a recent systems biology analysis of WNV infection in vivo revealed novel cross-talk between the RLR and IFN signaling pathways and the induction of inflammatory cytokines, as well as an unexpected role for natural killer cells in restricting WNV tropism [38].

There are several limitations to consider when interpreting large-scale ISG screens (Figure 2), particularly given the apparent lack of overlap in the sets of antiviral genes identified by different investigators [28-31]. First, as ISGs normally are co-induced by similar stimuli, a single ISG expressed in isolation (e.g. ectopic expression) may lack interactions with and regulation by other ISGs that are present in the context of a viral infection. Some ISGs may be active only under particular circumstances (cell type, stage of virus infection, expression of other infection-induced factors) and the effect any individual ISG may be small. The modest antiviral effects observed for most ISGs suggest that these molecules act in concert to produce a cellular environment that is refractory to viral replication. Second, large-scale screens have been conducted in cell lines with defective antiviral responses, (e.g. Huh7, HeLa, or STAT1 ${ }^{-/-}$fibroblasts). The dominant antiviral effector genes in these cells may not reflect those controlling viral replication in immune competent cells and tissues. Of particular relevance to WNV are antiviral effector molecules that are active in myeloid cells or neurons, the primary targets for WNV in vivo [1]. This issue is of great interest given recent studies demonstrating that the cerebral cortex and cerebellum have different basal levels of ISG expression and differential IFN responsiveness [39]. Specifically, tissuespecific epigenetic modifications result in relatively higher basal levels of ISG expression in neurons of the cerebellum compared to the cortex, although the upregulation of ISG expression is more evident in the cortex. The end-result is that cerebellar neurons are more resistant to infection by WNV and other RNA viruses [39]. These findings highlight celland tissue-specific differences in the antiviral response, which are critical for understanding viral tropism and the antiviral response in vivo. Third, ISG screens generally have been conducted using virulent strains of WNV. Since viral pathogenesis likely reflects an ability to overcome key immune restrictions, virulent strains may antagonize or avoid the antiviral effects of some ISGs in vitro. In fact, critical antiviral restriction factors might be missed by this approach, since stronger antiviral effects produce greater selective pressures for viral immune evasion. Therefore, attenuated virus strains may be useful as probes to identify novel antiviral restriction factors. As an example, a virulent strain of WNV commonly used for pathogenesis studies exhibited no phenotype in IFIT1 ${ }^{-/}$primary cells or mice; the role of IFIT1 as an antiviral effector was revealed by an attenuated genetic mutant virus that lacked $2^{\prime}-O$ methylation of its viral RNA cap structure $[34,40]$. 


\section{IFNs limit WNV neuroinvasion by tightening the blood-brain barrier}

IFN- $\alpha / \beta$ has been thought to control WNV and other viruses by two primary mechanisms: i) the induction of cell-intrinsic antiviral effectors that restrict different steps in virus replication and ii) modulation of the adaptive immune response. Recent work suggests that IFN- $\alpha / \beta$ may act by an additional, novel mechanism: controlling blood-brain barrier (BBB) permeability [41]. The BBB is a physical barrier formed by tight junctions between endothelial cells in the CNS microvasculature, with input from astrocyte foot processes. The BBB protects vulnerable CNS tissues from harmful substances in the peripheral circulation, including viruses [42]. Following inoculation by a mosquito, WNV infects keratinocytes and resident dendritic cells in the skin [43], traffics to draining lymph nodes, and establishes infection in other myeloid cells, which results in viremia [1]. WNV and other encephalitic flaviviruses cause CNS disease when they breach the BBB and infect neurons in the brain and spinal cord. The mechanisms by which WNV crosses the BBB remain unclear, but could include transit of free virions across a compromised barrier, trafficking of infected leukocytes from the periphery, or direct infection of the endothelial cells that comprise the BBB [44]. One study found that inflammatory cytokine production downstream of TLR3 signaling promoted BBB opening and WNV neuroinvasion [45], although a subsequent paper identified a protective role for TLR3 in limiting WNV pathogenesis [9]. Recent work has used in vivo and in vitro models to demonstrate that IFN- $\alpha / \beta$ signaling induces BBB tightening, thereby restricting WNV neuroinvasion. This tightening effect is rapid and involves rearrangement of endothelial cell junction proteins via Rho-Rac signaling pathways [41].

\section{The insect antiviral response to WNV}

While much attention has been given to the host response to WNV in humans and mice, there is a growing understanding of the insect antiviral response to arthropod-borne viruses, including WNV. The need to cycle between bird and mosquito hosts imposes evolutionary constraints on $\mathrm{WNV}$, including selection for viruses that are non-pathogenic in mosquitoes $[46,47]$. In addition to replicating in distinct cellular environments (e.g. temperature and lipid composition), WNV must evade both vertebrate and insect antiviral responses, including IFN and RNA interference (RNAi), respectively [48,49].

Drosophila systems have provided valuable models for understanding the insect response to viral infections, due to the wealth of genetic, developmental, and technical resources available [50]. Advantages of studying antiviral restriction factors in Drosophila include the ease with which cells in culture take up exogenous dsRNA, the availability of gene silencing reagents including whole-genome silencing screens, and the ability to validate in vitro findings in an animal model using existing mutant fly strains or rapidly generating new mutants of interest. A recent gene silencing screen in Drosophila DL1 cells identified putative WNV restriction factors; $86 \%$ of these have a human ortholog, suggesting commonalities between the antiviral pathways in insects and mammals [51]. In particular, the genes dRUVBL2, Tip60, and XPO1 shared antiviral activity in Drosophila, mosquitoes, human cells, and mouse primary neurons. The restriction factors identified in this approach surprisingly were enriched for nuclear functions such as RNA metabolism and transcription, 
suggesting that Drosophila-based screens may reveal novel pathways in cell-intrinsic antiviral immunity.

There has been an increasing ability to translate findings from Drosophila into the mosquitoes that serve as WNV vectors. For example, the secreted peptide Vago has antiviral activity in Drosophila [52], and recently was shown to restrict WNV infection in mosquito cells $[53,54]$. The inhibitory activity of Vago requires JAK-STAT signaling [53].

Furthermore, Vago production is induced in response to pathogen-sensing by Dicer-2, a DExD/H-box helicase that also initiates the antiviral RNAi response in insects and is homologous to mammalian RLRs [52,55]. Thus, while insects do not possess an IFN system, Vago may serve as an antiviral functional analog.

While Drosophila models have identified many host factors that are conserved in other insects and even in mammals, other studies have revealed mosquito restriction factors that were not evident from Drosophila-based approaches. For example, aae-miR-2940 is a micro RNA (miRNA) that promotes WNV replication and is downregulated by mosquito cells in response to WNV infection [56]. This miRNA is found in Aedes and Culex mosquitoes, but has no counterpart in Drosophila. Validation of Drosophila factors in mosquitoes, as well as characterizing mosquito-specific factors, will provide new insights into the interactions of WNV with its biologically relevant insect vectors.

\section{Conclusions}

Our knowledge of the host factors that control WNV infection has expanded greatly in recent years, due in part to the results of large-scale genetic screens to identify antiviral factors. Ongoing work is needed to translate lists of possible antiviral genes into testable hypotheses and to understand the mechanisms by which these factors limit viral pathogenesis in insects and mammals.

\section{Acknowledgments}

NIH grants U19 AI083019, U19 AI106772, R01 AI104972, and R01 AI104002 supported this work. WNV virion images were modeled from PDB 1K4R using the VIPERdb website (Vdb entry key 78).

\section{References}

- Of special interest

$\bullet$ Of outstanding interest

1. Suthar MS, Diamond MS, Gale M Jr. West Nile virus infection and immunity. Nat Rev Microbiol. 2013; 11:115-128. [PubMed: 23321534]

2. Colpitts TM, Conway MJ, Montgomery RR, Fikrig E. West Nile Virus: biology, transmission, and human infection. Clin Microbiol Rev. 2012; 25:635-648. [PubMed: 23034323]

3. Reisen WK. Ecology of West Nile virus in North America. Viruses. 2013; 5:2079-2105. [PubMed: 24008376]

4. Roehrig JT. West nile virus in the United States - a historical perspective. Viruses. 2013; 5:30883108. [PubMed: 24335779]

5. Murray KO, Ruktanonchai D, Hesalroad D, Fonken E, Nolan MS. West Nile virus, Texas, USA, 2012. Emerg Infect Dis. 2013; 19:1836-1838. [PubMed: 24210089] 
6. Bakonyi T, Ferenczi E, Erdelyi K, Kutasi O, Csorgo T, Seidel B, Weissenbock H, Brugger K, Ban E, Nowotny N. Explosive spread of a neuroinvasive lineage 2 West Nile virus in Central Europe, 2008/2009. Vet Microbiol. 2013

7. Ciccozzi M, Peletto S, Cella E, Giovanetti M, Lai A, Gabanelli E, Acutis PL, Modesto P, Rezza G, Platonov AE, et al. Epidemiological history and phylogeography of West Nile virus lineage 2. Infect Genet Evol. 2013; 17C:46-50. [PubMed: 23542457]

8. Frost MJ, Zhang J, Edmonds JH, Prow NA, Gu X, Davis R, Hornitzky C, Arzey KE, Finlaison D, Hick P, et al. Characterization of virulent West Nile virus Kunjin strain, Australia, 2011. Emerg Infect Dis. 2012; 18:792-800. [PubMed: 22516173]

9. Daffis S, Samuel MA, Suthar MS, Gale M Jr, Diamond MS. Toll-like receptor 3 has a protective role against West Nile virus infection. J Virol. 2008; 82:10349-10358. [PubMed: 18715906]

10. Suthar MS, Ma DY, Thomas S, Lund JM, Zhang N, Daffis S, Rudensky AY, Bevan MJ, Clark EA, Kaja MK, et al. IPS-1 is essential for the control of West Nile virus infection and immunity. PLoS Pathog. 2010; 6:e1000757. [PubMed: 20140199]

11. Szretter KJ, Daffis S, Patel J, Suthar MS, Klein RS, Gale M Jr, Diamond MS. The innate immune adaptor molecule MyD88 restricts West Nile virus replication and spread in neurons of the central nervous system. J Virol. 2010; 84:12125-12138. [PubMed: 20881045]

12. Town T, Bai F, Wang T, Kaplan AT, Qian F, Montgomery RR, Anderson JF, Flavell RA, Fikrig E. Toll-like receptor 7 mitigates lethal West Nile encephalitis via interleukin 23-dependent immune cell infiltration and homing. Immunity. 2009; 30:242-253. [PubMed: 19200759]

13. Errett JS, Suthar MS, McMillan A, Diamond MS, Gale M Jr. The essential, nonredundant roles of RIG-I and MDA5 in detecting and controlling West Nile virus infection. J Virol. 2013; 87:1141611425. [PubMed: 23966395]

14. Lazear HM, Pinto AK, Ramos HJ, Vick SC, Shrestha B, Suthar MS, Gale M Jr, Diamond MS. Pattern Recognition Receptor MDA5 Modulates CD8+ T Cell-Dependent Clearance of West Nile Virus from the Central Nervous System. J Virol. 2013; 87:11401-11415. [PubMed: 23966390]

15. Suthar MS, Aguirre S, Fernandez-Sesma A. Innate immune sensing of flaviviruses. PLoS Pathog. 2013; 9:e1003541. [PubMed: 24068919]

16. Fredericksen BL, Keller BC, Fornek J, Katze MG, Gale M Jr. Establishment and maintenance of the innate antiviral response to West Nile Virus involves both RIG-I and MDA5 signaling through IPS-1. J Virol. 2008; 82:609-616. [PubMed: 17977974]

17. Loo YM, Fornek J, Crochet N, Bajwa G, Perwitasari O, Martinez-Sobrido L, Akira S, Gill MA, Garcia-Sastre A, Katze MG, et al. Distinct RIG-I and MDA5 signaling by RNA viruses in innate immunity. J Virol. 2008; 82:335-345. [PubMed: 17942531]

18•. Schoggins JW, MacDuff DA, Imanaka N, Gainey MD, Shrestha B, Eitson JL, Mar KB, Richardson RB, Ratushny AV, Litvak V, et al. Pan-viral specificity of IFN-induced genes reveals new roles for cGAS in innate immunity. Nature. 2014; 505:691-695. Reveals that the DNA sensor cGAS restricts WNV infection in vitro and in vivo. [PubMed: 24284630]

19. You F, Wang P, Yang L, Yang G, Zhao YO, Qian F, Walker W, Sutton R, Montgomery R, Lin R, et al. ELF4 is critical for induction of type I interferon and the host antiviral response. Nat Immunol. 2013; 14:1237-1246. [PubMed: 24185615]

20. Cai X, Chiu YH, Chen ZJ. The cGAS-cGAMP-STING pathway of cytosolic DNA sensing and signaling. Mol Cell. 2014; 54:289-296. [PubMed: 24766893]

21. Zhong B, Yang Y, Li S, Wang YY, Li Y, Diao F, Lei C, He X, Zhang L, Tien P, et al. The adaptor protein MITA links virus-sensing receptors to IRF3 transcription factor activation. Immunity. 2008; 29:538-550. [PubMed: 18818105]

22. Shimizu A, Nakatani Y, Nakamura T, Jinno-Oue A, Ishikawa O, Boeke JD, Takeuchi Y, Hoshino H. Characterisation of cytoplasmic DNA complementary to non-retroviral RNA viruses in human cells. Sci Rep. 2014; 4:5074. [PubMed: 24875540]

23. Rubartelli A, Lotze MT. Inside, outside, upside down: damage-associated molecular-pattern molecules (DAMPs) and redox. Trends Immunol. 2007; 28:429-436. [PubMed: 17845865]

24. Samuel MA, Diamond MS. Alpha/beta interferon protects against lethal West Nile virus infection by restricting cellular tropism and enhancing neuronal survival. J Virol. 2005; 79:13350-13361. [PubMed: 16227257] 
25. Daffis S, Lazear HM, Liu WJ, Audsley M, Engle M, Khromykh AA, Diamond MS. The naturally attenuated Kunjin strain of West Nile virus shows enhanced sensitivity to the host type I interferon response. J Virol. 2011; 85:5664-5668. [PubMed: 21411525]

26. Sadler AJ, Williams BR. Interferon-inducible antiviral effectors. Nat Rev Immunol. 2008; 8:559_ 568. [PubMed: 18575461]

27. Schoggins JW. Interferon-stimulated genes: roles in viral pathogenesis. Curr Opin Virol. 2014; 6C: 40-46. [PubMed: 24713352]

28••. Schoggins JW, Wilson SJ, Panis M, Murphy MY, Jones CT, Bieniasz P, Rice CM. A diverse range of gene products are effectors of the type I interferon antiviral response. Nature. 2011; 472:481-485. A large-scale ectopic expression screen identifying ISGs that restrict many viruses, including WNV. [PubMed: 21478870]

29. Jiang D, Weidner JM, Qing M, Pan XB, Guo H, Xu C, Zhang X, Birk A, Chang J, Shi PY, et al. Identification of five interferon-induced cellular proteins that inhibit west nile virus and dengue virus infections. J Virol. 2010; 84:8332-8341. [PubMed: 20534863]

30. Li J, Ding SC, Cho H, Chung BC, Gale M Jr, Chanda SK, Diamond MS. A short hairpin RNA screen of interferon-stimulated genes identifies a novel negative regulator of the cellular antiviral response. MBio. 2013; 4:e00385-00313. [PubMed: 23781071]

31. Krishnan MN, Ng A, Sukumaran B, Gilfoy FD, Uchil PD, Sultana H, Brass AL, Adametz R, Tsui $\mathrm{M}$, Qian F, et al. RNA interference screen for human genes associated with West Nile virus infection. Nature. 2008; 455:242-245. [PubMed: 18690214]

32. Diamond MS, Farzan M. The broad-spectrum antiviral functions of IFIT and IFITM proteins. Nat Rev Immunol. 2013; 13:46-57. [PubMed: 23237964]

33. Szretter KJ, Brien JD, Thackray LB, Virgin HW, Cresswell P, Diamond MS. The interferoninducible gene viperin restricts West Nile virus pathogenesis. J Virol. 2011; 85:11557-11566. [PubMed: 21880757]

34. Szretter KJ, Daniels BP, Cho H, Gainey MD, Yokoyama WM, Gale M Jr, Virgin HW, Klein RS, Sen GC, Diamond MS. 2'-O methylation of the viral mRNA cap by West Nile virus evades ifit1dependent and -independent mechanisms of host restriction in vivo. PLoS Pathog. 2012; 8:e1002698. [PubMed: 22589727]

35. Samuel MA, Whitby K, Keller BC, Marri A, Barchet W, Williams BR, Silverman RH, Gale M Jr, Diamond MS. PKR and RNase L contribute to protection against lethal West Nile Virus infection by controlling early viral spread in the periphery and replication in neurons. J Virol. 2006; 80:7009-7019. [PubMed: 16809306]

36. Cho H, Shrestha B, Sen GC, Diamond MS. A role for Ifit2 in restricting West Nile virus infection in the brain. J Virol. 2013; 87:8363-8371. [PubMed: 23740986]

37. Suthar MS, Pulendran B. Systems analysis of West Nile virus infection. Curr Opin Virol. 2014; 6:70-75. [PubMed: 24851811]

38. Suthar MS, Brassil MM, Blahnik G, McMillan A, Ramos HJ, Proll SC, Belisle SE, Katze MG, Gale M Jr. A systems biology approach reveals that tissue tropism to West Nile virus is regulated by antiviral genes and innate immune cellular processes. PLoS Pathog. 2013; 9:e1003168. [PubMed: 23544010]

39•. Cho H, Proll SC, Szretter KJ, Katze MG, Gale M Jr, Diamond MS. Differential innate immune response programs in neuronal subtypes determine susceptibility to infection in the brain by positive-stranded RNA viruses. Nat Med. 2013; 19:458-464. Identifies CNS region-specific ISG expression profiles that contribute to WNV tropism in vivo. [PubMed: 23455712]

40. Daffis S, Szretter KJ, Schriewer J, Li J, Youn S, Errett J, Lin TY, Schneller S, Zust R, Dong H, et al. 2'-O methylation of the viral mRNA cap evades host restriction by IFIT family members. Nature. 2010; 468:452-456. [PubMed: 21085181]

41 • Daniels BP, Holman DW, Cruz-Orengo L, Jujjavarapu H, Durrant DM, Klein RS. Viral pathogenassociated molecular patterns regulate blood brain barrier integrity via competing innate cytokine signals. MBio. 2014; 5:e01476-01414. Demonstrates a novel antiviral mechanism of type I IFNs. tightening the blood-brain barrier. [PubMed: 25161189]

42. Spindler KR, Hsu TH. Viral disruption of the blood-brain barrier. Trends Microbiol. 2012; 20:282290. [PubMed: 22564250] 
43. Lim PY, Behr MJ, Chadwick CM, Shi PY, Bernard KA. Keratinocytes are cell targets of West Nile virus in vivo. J Virol. 2011; 85:5197-5201. [PubMed: 21367890]

44. Suen WW, Prow NA, Hall RA, Bielefeldt-Ohmann H. Mechanism of West Nile Virus Neuroinvasion: A Critical Appraisal. Viruses. 2014; 6:2796-2825. [PubMed: 25046180]

45. Wang T, Town T, Alexopoulou L, Anderson JF, Fikrig E, Flavell RA. Toll-like receptor 3 mediates West Nile virus entry into the brain causing lethal encephalitis. Nat Med. 2004; 10:13661373. [PubMed: 15558055]

46. Ciota AT, Ehrbar DJ, Matacchiero AC, Van Slyke GA, Kramer LD. The evolution of virulence of West Nile virus in a mosquito vector: implications for arbovirus adaptation and evolution. BMC Evol Biol. 2013; 13:71. [PubMed: 23514328]

47. Deardorff ER, Fitzpatrick KA, Jerzak GV, Shi PY, Kramer LD, Ebel GD. West Nile virus experimental evolution in vivo and the trade-off hypothesis. PLoS Pathog. 2011; 7:e1002335. [PubMed: 22102808]

48. Donald CL, Kohl A, Schnettler E. New Insights into Control of Arbovirus Replication and Spread by Insect RNA Interference Pathways. Insects. 2012; 3:511-533.

49. Kingsolver MB, Huang Z, Hardy RW. Insect antiviral innate immunity: pathways, effectors, and connections. J Mol Biol. 2013; 425:4921-4936. [PubMed: 24120681]

50. Xu J, Cherry S. Viruses and antiviral immunity in Drosophila. Dev Comp Immunol. 2014; 42:6784. [PubMed: 23680639]

51••. Yasunaga A, Hanna SL, Li J, Cho H, Rose PP, Spiridigliozzi A, Gold B, Diamond MS, Cherry S. Genome-wide RNAi screen identifies broadly-acting host factors that inhibit arbovirus infection. PLoS Pathog. 2014; 10:e1003914. A genome-wide gene silencing screen in Drosophila identifies host factors that restrict WNV infection in insects. [PubMed: 24550726]

52. Deddouche S, Matt N, Budd A, Mueller S, Kemp C, Galiana-Arnoux D, Dostert C, Antoniewski C, Hoffmann JA, Imler JL. The DExD/H-box helicase Dicer-2 mediates the induction of antiviral activity in drosophila. Nat Immunol. 2008; 9:1425-1432. [PubMed: 18953338]

53. Paradkar PN, Duchemin JB, Voysey R, Walker PJ. Dicer-2-dependent activation of Culex Vago occurs via the TRAF-Rel2 signaling pathway. PLoS Negl Trop Dis. 2014; 8:e2823. [PubMed: 24762775]

54. Paradkar PN, Trinidad L, Voysey R, Duchemin JB, Walker PJ. Secreted Vago restricts West Nile virus infection in Culex mosquito cells by activating the Jak-STAT pathway. Proc Natl Acad Sci U S A. 2012; 109:18915-18920. [PubMed: 23027947]

55. Zou J, Chang M, Nie P, Secombes CJ. Origin and evolution of the RIG-I like RNA helicase gene family. BMC Evol Biol. 2009; 9:85. [PubMed: 19400936]

56. Slonchak A, Hussain M, Torres S, Asgari S, Khromykh AA. Expression of mosquito microRNA Aae-miR-2940-5p is downregulated in response to West Nile virus infection to restrict viral replication. J Virol. 2014; 88:8457-8467. [PubMed: 24829359] 


\section{Highlights}

- Genetic screens have identified host factors restricting WNV infection in cells

- WNV infection paradoxically is restricted by cGAS, a DNA sensor

- Interferon- $\alpha / \beta$ tightens the blood-brain barrier, which limits WNV neuroinvasion 


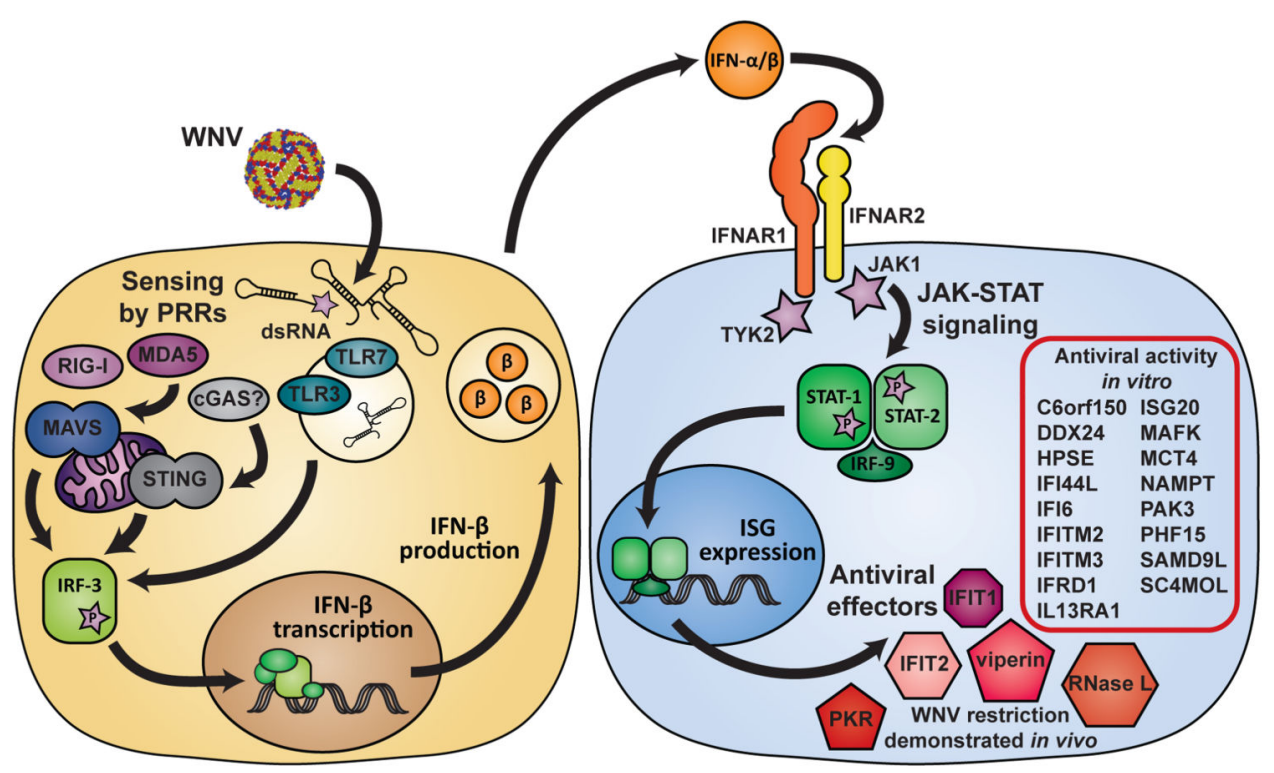

Figure 1. The IFN-mediated antiviral response to $\mathrm{WNV}$

WNV infection is sensed by pattern-recognition receptors (PRRs) including RIG-I-like receptors (RIG-I, MDA5) and Toll-like receptors (TLR3, TLR7). These signal to activate IRF-family transcription factors, which induce IFN- $\beta$ transcription and production. New evidence suggests that a DNA sensor, cGAS, also activates the antiviral response after WNV infection. IFN- $\alpha / \beta$ signals in an autocrine and paracrine manner to induce the expression of hundreds of IFN-stimulated genes (ISGs) that inhibit viral replication by a variety of mechanisms. Many ISGs have been shown to restrict WNV replication in vitro (a selection of which are listed), but few of these have confirmed roles in controlling WNV pathogenesis in vivo (e.g., PKR, IFIT2, viperin, and RNase L). Virulent strains of WNV evade the antiviral activity of IFIT1; only mutant viruses that lack $2^{\prime}-O$ methylation on the $5^{\prime}$ cap structure of their viral RNA are restricted by IFIT1. 


\section{Limitations of large-scale ISG screens}

1. Individually over-expressed ISGs lack interactions with and regulation by other ISGs present during viral infection
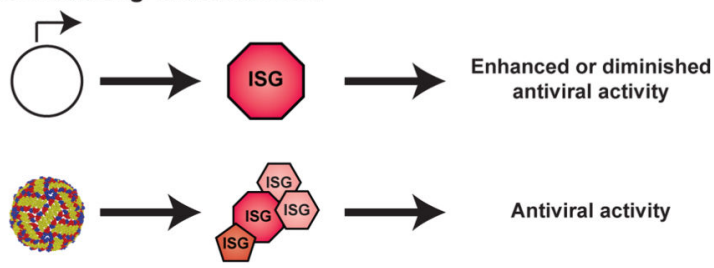

2. Different antiviral effectors may predominate in immune competent and differentiated cells, compared to immune deficient cell lines

HeLa Cell

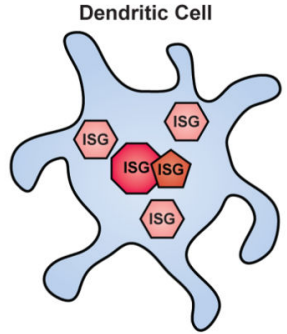

Cortical Neuron
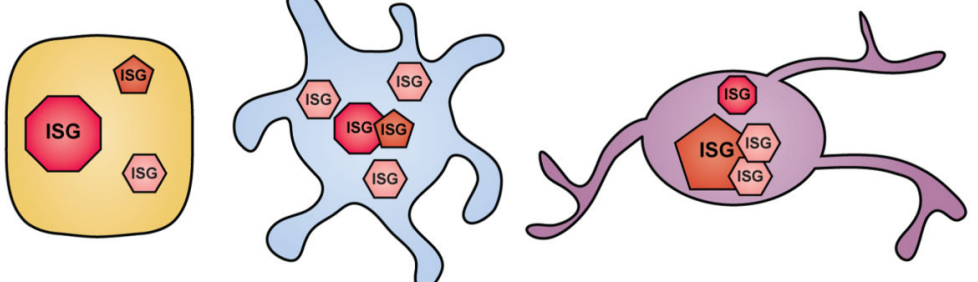

3. Virulent strains antagonize the antiviral response

Attenuated strain

Virulent strain
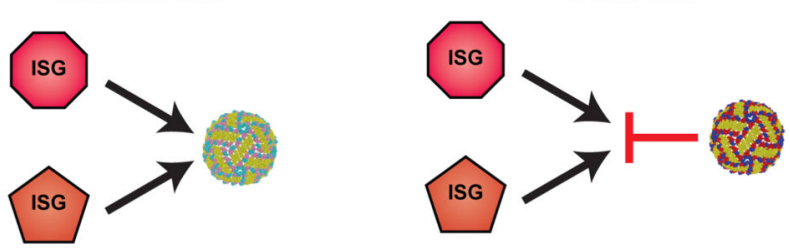

Figure 2. Limitations of genetic screens to identify antiviral interferon-stimulated genes (ISGs) Large-scale ectopic expression and gene silencing screens have provided new insights into the IFN-induced host factors that restrict infection by WNV and other viruses in vitro. However, the roles of these host factors in controlling WNV pathogenesis in vivo remain less clear, owing to several limitations of this approach. First, viral infection triggers global changes in cellular gene expression and produces an antiviral milieu that is absent in the context of ectopic expression of a single ISG. Second, the antiviral response in transformed or knockout cell lines used for genetic screens may not faithfully represent that found in differentiated and immune competent cells. Third, some restriction factors may remain undetected because their antiviral activities are antagonized by the virulent strain of virus used in the genetic screen. 